\title{
Penguatan Dakwah Digital PDM (Pimpinan Daerah Muhammadiyah) Kota Surakarta Melalui Website muhammadiyahsolo.com
}

\author{
Agus Triyono, Suranto, Kuswaji Dwi Priyono \\ Universitas Muhammadiyah Surakarta, Indonesia \\ agus.triyono@ums.ac.id
}

Received: $3^{\text {rd }}$ February 2020 | Accepted: $27^{\text {th }}$ July 2020 | Publihsed: $20^{\text {th }}$ August 2020

Key word:

new media;

dakwah

digitalitation;

PDM Kota

Surakarta

\section{Kata Kunci}

media baru;

digitalisasi

dakwah; PDM

Kota Surakarta

\section{Abstract}

Technological developments significantly makes da'wah evolve from offline to online using internet media. By the collaboration of da'wah and the internet, the values of Muhammadiyah Da'wah will be more easily dispersed and absorbed by the audience. The focus in this activity is to build a website system that becomes the means of digital da'wah, especially in the Distrcit Commitee of Surakarta. The method of implementation in this activity is FGD, website building, socialization, training and maintenance. In each activity, attended by representatives of Ortom, assembly, and Charity Enterprises Muhammadiyah (AUM). From the dedication activities that have been implemented can be concluded that the program has been running in accordance with the results of discussions between partners and executor. From the level of activity of each trainees in submitting the news is pretty good. This can be seen from the data contained in the website The significant increase in the number of articles containing information and articles uploaded at muhammadiyahsolo.com. Data from May - December 2019 shows an increase in the number of articles or news posted in total there are 142 manuscripts in a variety of categories : News, Tajdid, business charity schools and others with the number of view pages About 1500.

\section{Abstrak}

Perkembangan teknologi yang demikian pesat, membuat dakwah berkembang dari offline menjadi online dengan menggunakan media internet. Dengan mengkolaborasikan dakwah dan internet,, maka nilainilai dakwah Muhammadiyah akan lebih mudah tersebar dan diserap oleh khalayak. Fokus dalam kegiatan pengabdian ini adalah membangun sistem website yang menjadi sarana dakwah digital khususnya di Pengurus Daerah Muhammadiyah Kota Surakarta. Metode pelaksanaan dalam kegiatan adalah FGD, pembuatan website, sosialisasi, pelatihan dan pemeliharaan Dalam setiap kegiatan, dihadiri oleh perwakilan dari Ortom, Majelis, serta Amal Usaha Muhammadiyah (AUM). Kegiatan pengabdian yang sudah dilaksanakan dapat disimpulkan bahwa kegiatan telah berjalan sesuai dengan hasil diskusi antara mitra dan pelaksana. Dari aspek tingkat keaktifan dari masing-masing peserta pelatihan dalam mengirimkan berita cukup bagus. Hal ini bisa dilihat dari data yang ada di website adanya peningkatan signifikan jumlah artikel berisi informasi maupun artikel yang diunggah di muhammadiyahsolo.com. data dari bulan Mei - Desember 2019 menunjukan adanya peningkatan jumlah artikel ataupun berita yang 
diposting secara keseluruhan terdapat 142 naskah dalam berbagai macam kategori yakni: berita, tajdid, sekolah amal usaha dan lain-lain dengan jumlah view page sekitar 1500 kali. PDM Surakarta dalam hal ini Majelis Pustaka dan Informasi juga mengembangkan dakwah dengan saluran media sosial seperti IG, FB maupun memproduksi konten video di Youtube.

\section{PENDAHULUAN}

Kegiatan dakwah memiliki pemahaman sebagai suatu aktivitas mengajak manusia baik berupa tulisan, verbal maupun non verbal yang dapat berwujud tingkah laku yang dijalankan secara terprogram sebagai bentuk usaha mempersuasi orang baik individu maupun kelompok. Hal ini dilakukan agar muncul dalam diri objek suatu kesadaran, penghayatan, serta implementasi dalam kehidupan keseharian tanpa adanya unsur paksaan (Rozikan, 2017). Namun demikian, dalam kegiatan dakwah yang dilakukan oleh setiap muslim tidak boleh menyimpang dari pokok Al Quran dan Al Hadist. Pesan dakwah yang utama adalah mengajak manusia menuju perilaku yang baik dan meninggalkan kemungkaran. Sehingga, jika hal ini terjadi, maka masyakarat akan terbebas dari kebatilan dan kebodohan (Mutaqin, 2014).

Dakwah Islam merupakan sebuah kegiatan komunikasi, sehingga keberhasilan dakwah tergantung pada beberapa komponen yang mempengaruhinya yakni komunikator, komunikan, pesan serta media dakwah
(Aminudin, 2018). Harmonisasi semua elemen tersebut menentukan keberhasilan dari dakwah yang dilakukan. Memahami objek dakwah (komunikan) menjadi hal yang sangat penting dalam hal menentukan pesan sekaligus media yang akan digunakan sebagai sarana dakwah.

$$
\text { Perkembangan teknologi yang }
$$
demikian pesat, membuat dakwah berkembang dari offline menjadi online dengan menggunakan media internet. Saat ini, masyarakat tidak hanya menggunakan ulama sebagai rujukan dalam hal keagamaan, namun mulai bergesar pada merujuk internet dalam rangka memperoleh pengetahuan keagamaan. Internet menjadi media yang mudah dan lebih menarik untuk mendaptkan wawasan mengenai persoalan keagamaan (Basit, 2013).

Banyak organisasi dakwah yang menggunakan media baru untuk dakwah, baik Instagram (IG), website dan lain sebagainya. Hal tersebut misalnya kita bisa melihat dari daftar website Islam yang ada di Indonesia dari berdasarkan pemeringkatan dari http://alexa.com 
Tabel 1 : Daftar Website Berdasarkan Ranking dari Alexa.com

\begin{tabular}{cllrr}
\hline No & Nama & URL & ID Rank & Global Rank \\
\hline 1. & Kementrian Agama & kemenag.go.id & 76 & 3.606 \\
2. & Nahdlatul ulama & nu.or.id & 100 & 4.299 \\
3. & Muslim & muslim.or.id & 489 & 29.432 \\
4. & Rumaysho & rumaysho.com & 556 & 34.458 \\
5. & Eramuslim & eramuslim.com & 855 & 55.836 \\
6. & Muhammadiyah & Muhammadiyah.or.id & 2.237 & 167.509 \\
\hline
\end{tabular}

Sumber : Olahan pelaksana dari Alexa.com pada Desember 2019

Perkembangan masyarakat saat ini berada pada teknologi yang sangat cepat berkembang. Era industri 4.0 dan era informasi yang hebat harus dimanfaatkan pula untuk kepentingan dakwah. Terkait dengan hal tersebut, maka Pimpinan Daerah Muhammadiyah Kota Surakarta melalui Majelis Pustaka,Seni Budaya dan Informasi menyelenggarakan dakwah digital berbasis website.

Adapun basis website ini digunakan agar jangkauan pesan dakwah Muhammadiyah kota Surakarta bisa memberikan dampak positif terhadap kehidupan masyarakat luas. Maka dari itu, Majelis Pustaka Seni Budaya dan Informasi membuat website muhammadiyahsolo.com untuk menampung pesan dakwah dari seluruh komponen Muhammadiyah khususnya di kota Surakarta dan umumnya untuk masyarakat luas.

Alasan pemilihan objek ini didasarkan pada identifikasi masalah yang dilakukan oleh pelaksana dan mitra terhadap lemahnya aspek komunikasi dakwah yang dilakukan oleh PDM Kota Surakarta. Padahal sebagai sebuah organisasi dakwah dengan semangat berkemajuan, Muhammadiyah harusnya menjadi pelopor dan motor dalam digitalisasi dakwah khususnya berbasis website. Penelitan yang dilakukan oleh Pusat Studi Budaya dan Perubahan Sosial (PSBPS) menunjukan bahwa dalam konteks dakwah online, Muhammadiyah tertinggal dibandingkan dengan organisasi dakwah semisal NU maupun website yang tidak berafilisasi pada organisasi Islam tertentu (Hidayatullah dkk., 2020)

\section{METODE}

Beberapa metode yang dilakukan oleh pelaksana untuk mencapai tujuan pengabdian adalah berkerjasama dengan mitra yakni Majelis Pustaka dan Informasi (MPI) Kota Surakarta. Hasil diskusi dengan mitra, Semua kegiatan yang dilaksanakan secara intensif bekerja sama dengan MPI PDM Kota Surakarta dan melibatkan beberapa amal usaha Muhammadiyah khususnya yang berada 
dibawah koordinasi dengan PDM Kota Surakarta.

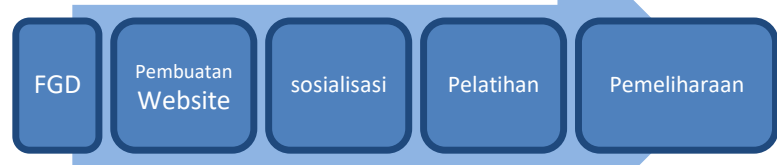

Gambar 1. Proses kegiatan pengabdian

\section{a) Focus Group Discussion (FGD)}

Kegiatan FGD ini dilakukan dalam rangka untuk mendapatkan pemahaman yang komprehensip terkait dengan perkembangan metode dakwah yang semakin beragam dan variatif. Dengan melakukan FGD ini, identifikasi masalah terkait pentingnya dakwah digital baik dari sisi kelemahan ataupun kekurangannya bisa diantisipasi sejak awal. Peserta dari kegiatan FGD ini adalah seluruh anggota MPI serta Pimpinan Cabang Muhammadiyah (PCM) serta Organisasi Otonom (Ortom) yang berada di bawah PDM Kota Surakarta.

\section{b) Pembuatan Website}

Website menjadi media kunci dalam rangka menjadi wadah yang mampu menjadi saluran publikasi kegiatan dakwah yang dilakukan oleh PDM Kota Surakarta. Penggunaan media website ini digunakan untuk menjawab tantangan perkembangan dakwah yang semakin dinamis.
Berdasarkan analisa kebutuhan yang dilakukan antara pelaksana dan mitra, disepakati bahwa konten website akanberisi tentang Berita, Tajdid, Amal Usaha, Pendidikan, Kesehatan, Dakwah, Sosial, Ortom, Tanya Ustadz, Galeri, About Us, Humor, Sosok, Agenda, Index

\section{c) Sosialisasi}

Setelah pembangunan website selesai, maka diperlukan kegiatan sosialisasi agar website menjadi sumber informasi dan rujukan khususnya bagi warga Muhammadiyah. Untuk proses sosialisasi website, pelaksana bersama mitra melakukan beberapa langkah yang diperlukan antara lain, pengadaan stiker website http://muhammadiyahsolo.com, sosialisasi ke warga Muhammadiyah khususnya guru dari tingkat SD-SMA.

\section{d) Pelatihan Rilis Berita dan Teknik Input Berita}

Website yang sudah dibangun tidak akan memiliki peran yang signifikan tanpa adanya konten yang menarik yang secara rutin diproduksi. Untuk itulah diperlukan pengisian konten website melibatkan semua amal usaha. Pelatihan ini dilakukan dengan dua tujuan, yakni penulisan rilis berita dan prosedur melakukan input ke materi website muhammadiyahsolo.com. 
e) Pemeliharaan

Pelaksana bersama mitra membentuk tim untuk yang berperan sebagai editor untuk proses keberlangsungan website dan dinamisasi dari konten website muhammadiyahsolo.com. Tim ini bertugas untuk mengatur sirkulasi konten yang disajikan agar menarik dan konten sesuai dengan kaidah yang telah ditentukan. Selain tim yang bersifat konten, kami juga membentuk tim maintenance website untuk menjaga keberlangsungan website muhammadiyahsolo.com dalam bidang perawatan sistem.

\section{HASIL}

Program pengabdian kali ini bertujuan untuk mengembangkan aspek dakwah berbasis media baru. Perkembangan teknologi yang demikian pesat, menuntut organisasi dakwah untuk berpikir kreatif dalam rangka menjangkau sasaran dakwah. Laporan penelitian tahun 2019 yang dirilis oleh APJII (Asosiasi Penyelenggara Jasa Internet Indonesia), penggunaan teknologi internet di Indonesia pada 2019 mengalami peningkatan 10,12\% dibandingkan dengan tahun 2018. Dari total jumlah penduduk 264 juta, sebanyak 171,17 juta jiwa telah mengakses internet dalam kehidupannya (Survei APJII: Penetrasi Pengguna Internet di Indonesia Capai 64,8\% - Katadata.co.id, t.t.).
Berdasarkan temuan Pew Internet \& American Life Project yang bekerjasama dengan Center for Research on Media, Religion and Culture menunjukan bahwa $64 \%$ responden menggunakan internet dengan tujuan agama. Tidak hanya itu, secara terperinci, tujuan agama tersebut dapat diturunkan kedalam beberapa yakni belajar agama, ibadah dan ritual, dakwah dan rekrutmen serta pembentukan komunitas online (NW dkk., 2004).

Berdasarkan hasil dari dua penelitian tersebut, tidak bisa dipungkiri bahwa sebagai sebuah organisasi dakwah, Muhammadiyah dalam sebuah tingkatan pengurus, dituntut untuk mengembangkan dakwah berbasis digital. Namun demikian, meski mengembangkan digitalisasi dakwah, Muhammadiyah bukan berarti meninggalkan dakwah konvensional berbasis masyarakat yang selama ini sudah dikembangkan.

Pengabdian kali ini melibatkan mitra MPI PDM Kota Surakarta. Majelis Pustaka dan Informasi mempunyai tugas utama yakni mewujudkan sistem informasi yang mencakup pengembangan pustaka dan informasi yang unggul, terintengrasi dan masif, sebagai visi pengembangan. Untuk melaksanakan tugas tersebut, maka majelis ini mempunyai program yakni berupaya mengembangkan kualitas dan kuantitas layanan pustaka, media, dan sistem 
informasi organisasi yang unggul dan berdaya saing dalam menjalankan fungsi syiar dan dakwah Persyarikatan. Dengan demikian, pemilihan mitra tersebut sangat tepat dalam rangka melakukan digitalisasi dakwah.

Hasil pengabdian yang dilakukan adalah dirilisnya website http://muhammadiyahsolo.com yang menjadi jendela dakwah digital bagi warga Muhammadiyah khususnya dan umat Islam pada umumnya. Pengabdian ini juga menghasilkan tim pengelola website yang memiliki tugas pokok dan fungsi melakukan maintenance website, menulis berita dan artikel, serta berinteraksi dengan pertanyaan dari pengunjung.

\section{PEMBAHASAN}

Kegiatan pengabdian dilakukan dengan kolaborasi antara pelaksana dan mitra dalam beberapa kegiatan yaitu.

a) Focus Group Discussion

Kegiatan ini dilaksanakan pada tanggal 3 Mei 2019, bertempat di Balai Muhammadiyah PDM Kota Surakarta yang dihadiri oleh pengurus Muhammadiyah Ranting, Cabang dan Daerah, Amal Usaha Muhammadiyah serta Organisasi Otonom di lingkup Muhammadiyah Kota Surakarta. Pelaksana juga hadir dalam kegiatan tersebut sebagai fasilitator yang memaparkan terkait dengan bagaimana perkembangan metode dakwah secara digital. Secara umum, berdasarakan penelitian yang dilakukan pada tahun 2017 , posisi Muhammadiyah dalam pengelolaan website masih tertinggal dibandingkan dengan organisasi dakwah yang lain maupun website yang tidak berafilisasi pada organisasi dakwah.

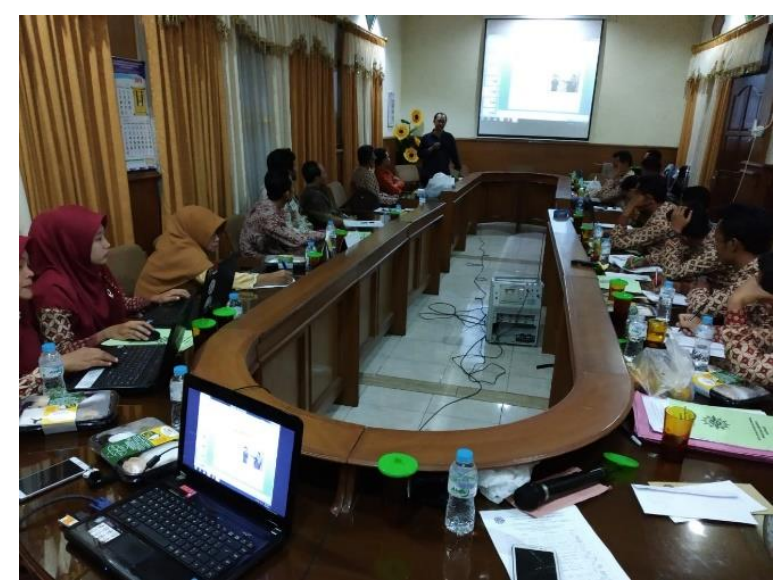

Gambar 2. Suasana FGD

Kegiatan FGD ini dilatar belakangi perkembangan oleh pesatnya perkembangan teknologi bahkan menyentuh pada ranah dakwah Islam. Sehingga, dakwah digital perlu mendapat perhatian serius bagi jajaran pengurus organisasi. Berbagai terobosan penggunaan media baru sebagai media dakwah ditengah era informasi dan teknologi perlu dilakukan agar pesan dakwah bisa tersampaikan kepada objek dakwah. Dengan demikian, semangat membangun kehidupan masyarakat berkemajuan bisa terwujud. 
b) Pembuatan Website

Tahapan pembuatan website dimulai dari perancangan desain website yang akan digunakan. Penggunaan media ini untuk menjawab tantangan perkembangan dakwah. Setelah desain website selesai, kemudian dilanjutkan pembelian domain dot org dan dot id serta pembuatan website muhammadiyahsolo.com. Pemilihan domain .com ini didasarkan pada pertimbangan kepopulerannya dibandingkan dengan domain yang lain.

Berdasarkan analisa kebutuhan yang dilakukan antara pelaksana dan mitra, disepakati bahwa konten website akanberisi tentang Berita, Tajdid, Amal Usaha, Pendidikan, Kesehatan, Dakwah, Sosial, Ortom, Tanya Ustadz, Galeri, About Us, Humor, Sosok, Agenda, Index. Proses pengisian konten dalam website membutuhkan waktu kurang lebih dua bulan sejak dibangunnya sistem dengan melibatkan Budi Cahyono salah satu webmaster dari Harian Solopos.

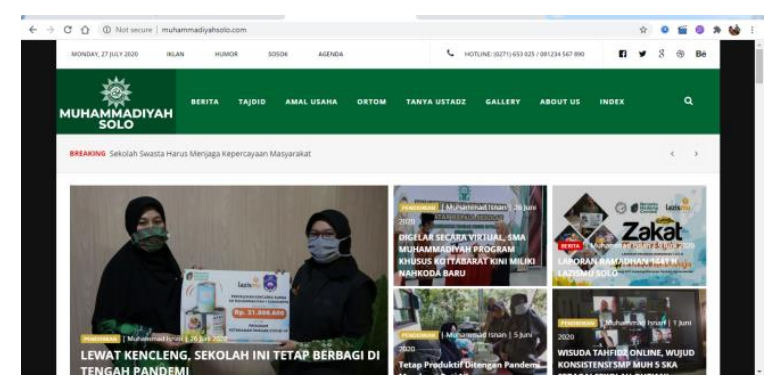
Gambar
3.
Tampilan
website

Sebagai sebuah website yang memuat profil organisasi, dibutuhkan informasi lembaga yang valid dan akurat. Terkait hal tersebut, terdapat beberapa proses yang dilakukan untuk memenuhi target informasi namun tetap mengedepankan akurasi informasi. Pelaksana dan mitra melakukan penelusuran data arsip yang tersimpan di ruang perpustakaan yang dikelola oleh Majelis Pustaka.

Secara bersamaan, kami juga menjalin komunikasi dengan Majelis, Lembaga, Ortom, Amal Usaha yang ada di Lingkungan PDM Solo guna pengumpulan informasi profil organisasi. Dalam rangka meningkatkan partisipasi lembaga dibawah naungan PDM Surakarta, kami juga memberikan hak kepada Majelis , Lembaga, Ortom dan Amal usaha untuk bisa memiliki user dan password sendiri di dalam website muhammadiyahsolo.com sehingga sewaktu waktu bisa mengupload data sendiri. Namun demikian, mitra tetap melakukan pengawasan secara berkala dalam rangka menjaga kualitas informasi yang diunggah.

\section{c) Sosialisasi}

Website yang sudah dibuat tidak akan berdampak signifikan jika tidak disertai dengan publikasi/sosialisasi kepada khalayak mengenai keberadaan website 
tersebut. Terlebih dalam era yang serba digital, persaingan antar website dalam rangka menaikan jumlah pengunjung sangat kompetitif. Masing-masing dari pengelola melakukan berbagai macam cara untuk menaikan kunjungan seperti penggunaan strategi memaksimalkan SEO (Search Engine Optimation), memperbaiki tampilan website, mempercepat kecepatan website serta melakukan sharing melalui media sosial (Setyaningsih dkk., 2012).

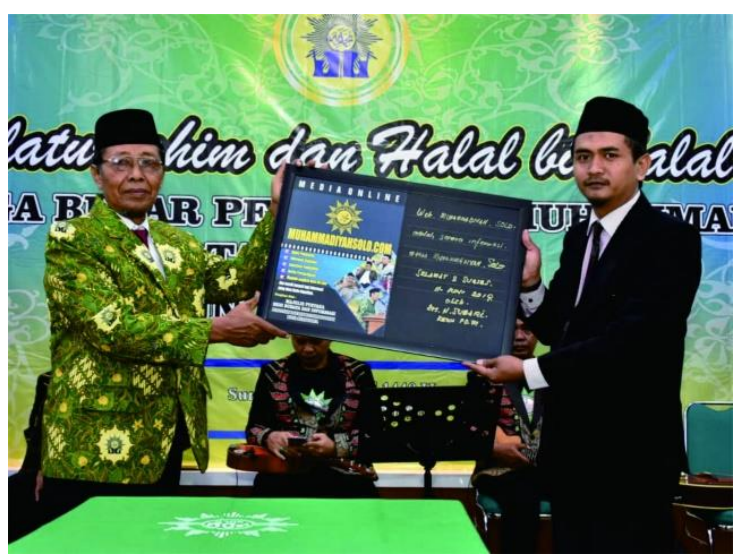

Gambar 4. Sosialisasi Website

Website muhammadiyahsolo.com tergolong baru, maka proses sosialisasi dilakukan dengan beberapa langkah yang dilakuan antara lain melalui penyelenggaraan FGD, pembuatan stiker muhammadiyahsolo.com sejumlah 100, MMT untuk launching website,dan pembuatan modul pelatihan. Untuk memperluas sosialisasi, secara khusus kegiatan sosialisasi pada tanggal 11 Juni 2019 didokumentasikan dan diupload di youtube dengan

link:
https://youtu.be/DVvgWYsG2MU.

Sosialisasi yang dibarengkan dengan kegiatan halal bi halal ini dilakukan dengan mengundang guru mulai dari tingkat SDSMA di lingkungan Amal Usaha Muhammadiyah se Surakarta.

d) Pelatihan Rilis Berita dan Teknik Input Berita

Pelatihan ini dilakukan dengan dua tujuan, yakni penulisan rilis berita dan prosedur melakukan input ke materi website muhammadiyahsolo.com. kegiatan ini dilaksanakan sebanyak tiga kali. Pertama dengan sasaran peserta sejumlah 21 orang dari Majelis, Cabang, dan Lembaga yang diselenggarakan pada tanggal 3 Agustus 2019. Kedua, dengan sasaran delegasi dari AUM Sekolah Dasar Muhammadiyah se-Surakarta sejumlah 15 orang yang diselenggarakan pada tanggal 31 Agustus 2019 bertempat di Balai Muhammadiyah Surakarta.

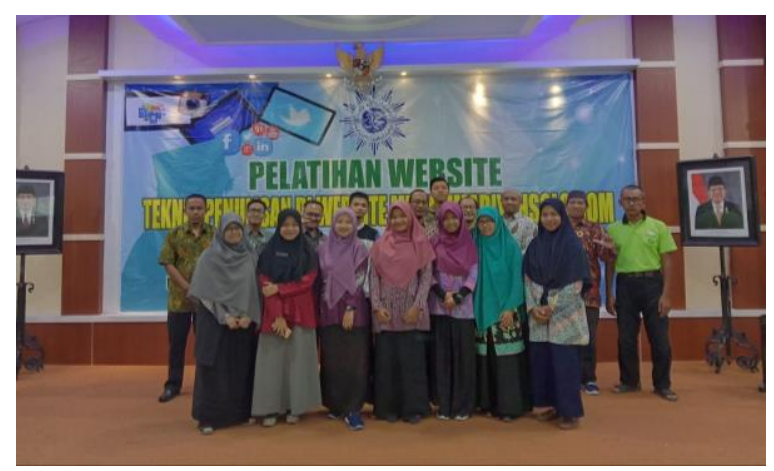

Gambar. 5. Pelatihan Teknis Penulisan Rilis Berita

Ketiga dengan sasaran AUM sekolah tingkat SMP/MTs, SMA/SMK/MA 
pada tanggal 12 September 2019 bertempat di balai Muhammadiyah Surakarta sejumlah 19 orang. Adapun untuk pemateri dalam pelatihan tersebut adalah Syifaul Arifin (wartawan dari Solopos) dan Syafruddin (Majelis Pustaka,Seni Budaya dan Informasi PDM Surakarta). Untuk konten pelatihan berisi teknik penulisan press rilis, berita yang menarik serta teknik memasukan berita di tampilan website muhammadiyahsolo.com

Dalam melaksanakan kegiatan kali ini, pelaksana juga melibatkan lembaga dan Amal Usaha Muhammadiyah yang berada dilingkungan PDM Kota Surakarta dalam berbagai program yakni pelatihan penulisan berita serta pembuatan user dan password untuk submit naskah berita di website www.muhammadiyahsolo.com.

e) Pemeliharaan

Untuk proses keberlangsungan website dan dinamisasi dari konten website muhammadiyahsolo.com, maka pelaksana bersama mitra membentuk tim untuk yang berperan sebagai editor. Tim ini bertugas untuk mengatur sirkulasi konten yang disajikan agar menarik dan konten sesuai dengan kaidah yang telah ditentukan. Selain tim yang bersifat konten, kami juga membentuk tim maintenance website untuk menjaga keberlangsungan website muhammadiyahsolo.com dalam bidang perawatan dan update sistem.

Secara umum, untuk proses pemeliharaan dibantu oleh 90 orang yang terbagi dalam beberapa bagian. Pertama, 2 orang berstatus sebagai administrator/super user yang mempunyai hak untuk melakukan update website, membuat user, mengedit dan menghapus artikel, mengisi artikel/berita serta yang tidak kalah penting adalah memberikan persetujuan publikasi terhadap kontribusi yang dikirimkan oleh kontributor.

Kedua, 10 orang bertindak sebagai penyunting yang mempunyai akses untuk memberi persetujuan terhadap setiap artikel yang telah di kirim oleh pihak kontributor untuk bisa dipublikasikan, mengisi artikel / berita, serta bisa menghapus dan mengedit artikel jika kontribusi yang masuk perlu mendapat perbaikan. Terakhir adalah 77 orang sebagai kontributor yang berasaladari Majelis, Lembaga, Ortom dan Amal Usaha. Sebagai kontributor, mereka hanya mempunyai hak untuk membuat artikel atau berita saja namun tidak mempunyai otoritas untuk mempublikasikannya.

\section{Digitalisasi Dakwah}

Hasil kegiatan dari pembuatan website sekaligus pelatihan operasionalnya terlihat cukup signifikan. Hal ini terlihat dari setiap lembaga dan Amal Usaha 
Muhammadiyah di lingkungan PDM Kota Surakarta sudah memiliki user dan password masing-masing sehingga dengan kepemilikan user tersebut, maka sekarang lembaga dan Amal Usaha bisa mengirimkan kontribusi secara langsung ke dalam website untuk kemudian di verifikasi oleh Super Admin lalu ditampilkan di website.

Dari aspek tingkat keaktifan dari masing-masing peserta pelatihan dalam mengirimkan berita cukup bagus. Hal ini bisa dilihat dari data yang ada di website adaya peningkatan signifikan jumlah artikel berisi informasi maupun artikel yang diunggah di muhammadiyahsolo.com. data dari bulan Mei - Desember 2019 menunjukan adanya peningkatan jumlah artikel ataupun berita yang diposting secara keseluruhan terdapat 142 naskah dalam berbagai macam kategori yakni : berita, tajdid, sekolah amal usaha dan lain-lain dengan jumlah view page sekitar 1500.

Keterlibatan dari lembaga dibawah PDM juga cukup tinggi. Dari postingan yang ada, user yang mengunggah informasi sangat beragam, mulai dari Admin, SMA Muhammadiyah , SMP Muhammadiyah PK, maupun dari Majelis yang ada di PDM. Sehingga konten website tidak hanya berisi seputar informasi kegiatan, namun juga memuat (Umar dkk., 2016) pandangan atau ideologi Muhammadiyah selaku organisasi Islam. Hal ini sebagaimana tujuan dari media massa yang tidak hanya sebagai alat penyampai informasi, namun juga menampilkan ideologi ataupun pandangan yang dianut (Muslim, 2013).

Hal tersebut sebagaimana terlihat dalam fenomena yang terjadi di Timur Tengah pada saat terjadinya Arab Spring yang dimulai pada tahun 2011 di Tunisia. Saat itu, internet maupun media sosial menjadi sarana untuk menjadi jembatan yang menghubungkan para aktivis di satu Negara dengan aktivis dibelahan Negara yang lain dalam menyebarkan spirit dan ideologi perubahan (Umar dkk., 2016).

Perkembangan digitalisasi dakwah adalah sebuah keniscayaan yang tidak bisa dipungkiri. Sebagai lembaga dakwah, Muhammadiyah dengan gagasan berkemajuan berkepentingan untuk melakukan pembaharuan dalam konteks pengembangan strategi dakwah. Dengan demikian kegiatan pengabdian ini mempunyai dampak yang sangat penting.

Saat ini, kegiatan dakwah yang dilakukan oleh Muhammadiyah di Surakarta dapat lebih terpublikasi secara maksimal dengan menggunakan media website. Jika sebelumnya kita hanya sekedar menjadi pembaca berita, kini mitra bisa juga melakukan produksi konten berita dan diunggah ke website. Dengan 
demikain, publikasi kegiatan dakwah yang dilakukan oleh Amal Uaha dapat tersebar melalui website dan bisa dikonsumsi oleh khalayak yang lebih luas.

\section{KESIMPULAN}

Dari kegiatan pengabdian yang sudah dilaksanakan dapat disimpulkan bahwa program telah berjalan sesuai dengan rencana yang dimulai dari perancangan website, identifikasi peluang dakwah digital melalui FGD, pelatihan penulisan berita dan unggah ke website sampai dengan publikasi kegiatan AUM melalui www.muhammadiyahsolo.com.

Namun demikian, pelaksana menyadari betul bahwa dibutuhkan perawatan website baik berupa pengisian konten secara rutin.

\section{SARAN}

Update konten yang dilakukan secara berkala mempengaruhi ketertarikan orang untuk mengunjungi sebuah website. Konten yang sudah diupdate, hendaknya harus didistribusikan melalui jejaring media sosial yang dimiliki oleh warga Muhammadiyah, khususnya AUM yang mengunggah berita tersebut. Sehingga, tingkat penyebaran informasi akan lebih maksimal dan jumlah pengunjung website juga akan meningkat.
Dari sisi ketersediaan media, hendaknya PDM Surakarta dalam hal ini Majelis Pustaka dan Informasi juga mengembangkan dakwah dengan saluran media sosial seperti IG, FB maupun memproduksi konten video di Youtube. Jika manajemen pengelolaan dilaksanakan dengan maksimal, maka pengaruh dakwah Muhammadiyah akan semakin dirasakan oleh objek dakwah.

Akan tetapi, yang paling utama dari kesemua proses tadi adalah PDM Kota Surakarta harus berkolaborasi dengan semua amal usaha yang berada dibawahnya. Hal ini karena amal usaha inilah yang akan berkontribusi dalam pengisian konten baik di www.muhammadiyahsolo.com maupun media sosial yang akan dikembangkan.

\section{DAFTAR PUSTAKA}

Aminudin, A. (2018). MEDIA DAKWAH. Al-MUNZIR, 9(2), 192-210. ttps://doi.org/10.31332/am.v9i2.786

Basit, A. (2013). Dakwah Cerdas di Era Modern. Jurnal Komunikasi Islam, 3(1), Article 1. https://doi.org/10.15642/jki.2013.3.1 Hidayatullah, M. S., Dimyathi, M. S., Abdullah, Zubair, \& Handayani, R. (2020). The Cyber Islam Contestation In Indonesia. International Journal of Advanced 
Science and Technology, 29(7), 34-

44.

http://sersc.org/journals/index.php/IJ

AST/article/view/13167

Muslim. (2013). Konstruksi Media Tentang

Serangan Israel Terhadap Lebanon.

Jurnal Studi Komunikasi dan Media, 17, 75-92.

Mutaqin, Z. (2014). Strategi dakwah KH

Chudlori di masyarakat kabupaten

Magelang [PhD Thesis]. UIN

Walisongo.

NW, 1615 L. St, Suite 800Washington, \&

Inquiries, D. 20036USA202-419-

4300 | M.-857-8562 | F.-419-4372 |

M. (2004, April 7). 64\% of online

Americans have used the Internet for

religious or spiritual purposes. Pew

Research Center: Internet, Science \&

Tech.

https://www.pewresearch.org/internet /2004/04/07/64-of-online-americanshave-used-the-internet-for-religiousor-spiritual-purposes/

Rozikan, M. (2017). Transformasi Dakwah Melalui Konseling Islami. INJECT

(Interdisciplinary Journal of

Communication), 2(1), 77-98.

Setyaningsih, D. T., Wintolo, H., \&

Nugraheny, D. (2012). Penerapan

Seo (Search Engine Optimization)

Menggunakan Teknik Together in a

Single Connection (Tsc) Dalam
Meningkatkan Kunjungan Pada

Sebuah Blog. Compiler, 1(2), 9-20.

https://doi.org/10.28989/compiler.v1i

\subsection{3}

Survei APJII: Penetrasi Pengguna Internet di Indonesia Capai 64,8\%-

Katadata.co.id. (t.t.). Diambil 4

Oktober 2020, dari

https://katadata.co.id/sortatobing/digi

tal/5e9a51915cd3b/survei-apjii-

penetrasi-pengguna-internet-di-

indonesia-capai-648

Umar, Ahmad. R. M., Darmawan, A. B., Sufa, F. S., \& Ndadari, G. L. (2016).

Media Sosial dan Revolusi Politik:

Memahami Kembali Fenomena

“Arab Spring” dalam Perspektif

Ruang Publik Transnasional. Jurnal

Ilmu Sosial dan Ilmu Politik, 18(2),

114.

https://doi.org/10.22146/jsp.13130 